\title{
Peertechz
}

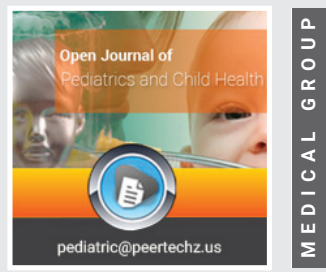

\section{Behavioural disorders in}

\section{children and adolescents:}

Definition, clinical contexts, neurobiological profiles and

\section{clinical treatments}

\author{
Giulio Perrotta ${ }^{1 *}$ and Gianfranco Fabiano ${ }^{2}$ \\ ${ }^{1}$ Psychologist sp.ing in Strategic Psychotherapy, Forensic Criminologist, Legal Advisor sp.ed SSPL, \\ Researcher, Essayist, Institute for the study of psychotherapies - ISP, Via San Martino della Battaglia \\ no. 31,00185 , Rome, Italy \\ ${ }^{2}$ Psychologist sp.ing in psychotherapy, Autogenic training conductor and Strategic counselor, Institute \\ for the study of psychotherapies - ISP, Via San Martino della Battaglia no. 31, 00185, Rome, Italy
}

Received: 11 February, 2021

Accepted: 17 March, 2021

Published: 23 March, 2021

*Corresponding author: Dr. Giulio Perrotta, Psychologist sp.ing in Strategic Psychotherapy, Forensic Criminologist, Legal Advisor sp.ed SSPL, Researcher, Essayist, Institute for the study of psychotherapies - ISP, Via San Martino della Battaglia no. 31, 00185, Rome, Italy, Tel. No: +39 3492108872;

E-mail:info@giulioperrotta.com

ORCID: https://orcid.org/0000-0003-0229-5562

https://www.peertechzpublications.com

Check for updates

\section{Abstract \\ Starting from the general concept of behaviour disorder, in childhood, preschool and adolescence, in this work the descriptive boundaries of all diagnostic hypotheses are defined, with an orientation for clinical, neurobiological and therapeutic treatment, not leaving out the socio-cultural, educational and family contexts inherent to the growth of the minor. In the last part of the work the reflexive cues are concentrated on the best theories and techniques of approach in the analysed species cases.}

\section{Contents of the manuscript}

\section{Behaviour and emotions in behaviour disorders: Short narrative}

Behaviour represents the set of behaviours that define the way an individual acts and reacts in relation to his or her surroundings and the individuals who are part of them. It is therefore the set of external manifestations of an individual that define the temperament (understood as the set of innate, genetically determined tendencies of the individual to react to environmental stimuli in certain ways) and the character (understood as the unitary and organized complex of the psyche in direct relation with the environment) and the experiences (the emotions recorded in the memory of interactions) and therefore the personality [1].

From the ashes of structuralism, always starting from the introspective assumption, the behaviourist current was born, which focused on manifest behaviour. In particular, Pavlov (1849-1936) focused on the mechanism of conditioning (1903), starting from the Russian studies of Secenov's "reflexological current" (1860). Like him, in the same years, so did Bechterev. Famous is his classic experiment with the dog (so called "the dog"). classic conditioning) to demonstrate the existence of the conditioned/conditioned reflex, i.e. with a natural stimulus (conditioned stimulus) one is able to provoke the occurrence of a certain involuntary reaction (unconditioned response), such as salivation, pupillary contraction or eye closure: $<<$ if we associate a conditioned stimulus (sound) with the unconditioned stimulus (food), a sufficient number of times, the dog will tend to associate the 2 stimuli, and give them the same meaning, causing an involuntary response (salivation) >>. In more recent years, Watson (1878-1958) focused on the stimulusresponse theory (S-R), but omitted mental processes (1913). He expressed his doubts about the introspective method and the results of primate experiments in their natural environment. 
According to this author, the acquisition of language takes place precisely through conditioning. Thorndike (1874-1949), later on, focused on the mechanism of learning, not using introspection but instead favouring observable behaviour. On this basis he elaborated three laws: a) first law (of frequency), according to which learning is gradual and improves with repetition; b) second law (of contiguity), according to which the shorter the interval of time between stimulus and response, the greater will be the learning; c) third law (of effect), according to which if the stimulus produces a response that produces a new behaviour similar to the previous one, the learning will be greater. Always Thorndike then coined the "halo effect" to designate a psychological attitude consisting in the automatic tendency, during the evaluation of a person, to associate to a positive quality (e.g. physical beauty) other positive aspects without any real correlation with that quality (e.g. sympathy, intelligence, competence or reliability). It can be considered an important and widespread example of "bias" operated on an ineffective heuristic basis. Hull (1940-1960) still concentrated on the themes of learning and behaviour, theorizing the assumption that the force of habit is directly proportional to the number of associations between stimulus and response that have been reinforced. Skinner (1940-1960) then focused on the cause-effect mechanism, introducing the principle of reinforcement. operative - active conditioning): a) human behaviours are predictable and controllable through an appropriate management of stimuli and reinforcements (shaping); b) operative or associative learning foresees the active, direct and conscious participation of the subject who acts as a consequence of positive reinforcements (reward) or negative reinforcements (punishment), as can be seen from the mouse experiment with cheese: <<a hungry rat, which moves in the Skinner Box, is conditioned to lower a lever, when it receives food, while it receives a shock if it stops touching it >>; c) Skinner finally takes his cue from Thorndike who years before had already invented the Puzzle Box: a cage from which a hungry cat learns progressively lowering with one paw the lever, which acts as a handle on the exit door, to reach the food outside. They both assumed that to learn you had to make mistakes, make mistakes; however, Skinner perfected this theory, thanks in part to his media success [1].

At the base of human action, however, are the emotions, understood as psychic processes provoked by a relevant eventstimulus able to stimulate physiological and bodily changes), which nourish needs and necessities according to a precise scheme (which originates from the unconsciousness) [2].

The recent interest in the study of emotions stems from the critique of Western thought, which has always contrasted reason with emotions, where in the former the noble part of man resided and in the latter the instinctive animalistic part to keep at bay. Today, different spheres of knowledge lead us to consider emotions as a form of cognitive and emotional communication. Emotional attachment to other individuals and the various types of emotional involvement influence a relevant portion of human behaviour [3].

Precisely for these reasons it is necessary to introduce the present work by briefly considering the evolution of thought on emotions, according to the main theories [4-10]:

\section{The classical theories}

a) James-Lange's theory: The psychologist James and the physiologist Lange, at the same time independently of each other, proposed similar theories on emotion, which is why it is called James-Lange theory. Their theory was opposed to that of common sense: According to them we do not weep because we are sad, but we feel sad because we cry; we do not tremble because we are scared, but we feel fear because we are shaking, and so many other examples. So according to this sequentiality, the emotional reaction depends on how the sensations are interpreted on a physical level.

b) The Cannon-Bard theory: Cannon, in 1927, published a critique of the James-Lange theory. Cannon discovered that the same state of activation of the sympathetic nervous system can be present in many different emotions. Thanks to these studies, Bard (1929) further elaborated this theory, according to which it is the thalamus that plays a critical role in emotional experience. For Bard, the nerve impulses that make sensory information pass through the thalamus are then retransmitted. He receives this input upwards in the cortex (causing a subjective emotional experience) and downwards in the muscles, glands and visceral organs (producing physiological changes). Cannon and Bard argued that the subjective and physiological components of emotion are simultaneous, disagreeing with James, who argued that physiological modifications precede and activate subjective states.

c) Schachter-Singer's theory: According to Schachter, one feels an emotion when choosing a cognitive label to designate a diffuse state of physiological activation to which we give the name of a particular sensation. Unlike James, Schachter does not advance the hypothesis that physiological sensations are emotions and that each emotion is accompanied by differentiated physiological modifications. Schachter suggests instead, that the state of activation is only a generalised activation of the autonomic nervous system, until we connect it cognitively to an interpretation by associating it with an emotion. For example, the judgment: "I have stomach cramps because this man is threatening me" will be followed by a feeling of fear. However, no emotions will be felt if external stimuli are not cognitively associated with the state of activation. It may happen, for example, that I notice that I have a stomachache and that the individual seems very irritated, but these two unrelated events do not cause any emotion.

\section{Modern theories}

a) The neurobiological approach: In 1980, Zajonc argues that emotions can be provoked even in the absence of high cognitive or perceptual involvement. Sometimes, for example, we feel an immediate sympathy for someone crossing a room or an aversion to someone else, for the way they answer the phone. In 1998, Le Doux confirmed how anger and fear can be directed from the thalamus to the amygdala, making an immediate evaluation possible and often producing an immediate attack/ fuge response, confirming what Zajonc said.

b) The cognitivist approach: According to Lazarus (1982) for an emotion to appear, thought is necessary and sufficient, that is, 
cognitive evaluation. Lazarus hypothesizes that our emotional experiences are always the result of thought, that is, of a cognitive evaluation of the meaning of the events responsible for our state in the here and now. He also argues that before we experience a normal emotion we evaluate events quickly or unconsciously, basing our thoughts on minimal information, using irrational premises. Cognitive evaluations that form very quickly and provoke an instantaneous emotional response such as "The wolf is about to attack me" are called warm cognitive processes and are the precursors of emotion. Other, slower cognitive processes such as "That wolf has a brown fur" do not arouse any emotion and are therefore called cold cognitive processes. This is why hot cognitive processes always precede emotions. Thanks to the work of different authors it has been understood that some emotions can be defined as innate, which is why the dichotomy between sensation and cognition is overcome.

c) The modern psychoanalytic approach: In psychoanalysis, emotions have always played a central role both in theory and in its clinical applicability, attributing to relational trauma a series of serious personality disorders and psychotic dissociation. Without retracing all the various stages in the history of psychoanalysis, let us examine two of the exponents of contemporary psychoanalysis: Stern who speaks of affective tuning and Hill who speaks of affective regulation. Through these two theories we have understood how emotion can be defined as a form of implicit communication capable of arousing certain affections in the other leading him to action, just as it happens between the manifestation of emotion in the child through crying and the mother's response.

d) The evolutionary theory: Ekman, in 2008, reviewed basic emotions through the observation of facial expressions in different cultures, realized that we have a significant number of innate emotions. Regardless of their culture, children manifest emotions in interactions with caregivers from birth. Seven primary or basic emotions were identified from this study:

- anger, generated by frustration that can manifest itself through aggressive behaviour;

- fear, aimed at the survival of the subject in a dangerous situation;

- sadness, generated as a result of loss or an unfulfilled goal;

- joy, positive state of mind of those who consider their desires satisfied;

- surprise, it originates from an unexpected event, followed by fear or joy;

- contempt, feeling and attitude of total lack of esteem, disdainful rejection of people or things considered despicable;

- disgust, aversion or physical or moral repugnance coming from satiety, or from discontent or resentment.
Subsequently, social interaction produces combinations of primary emotions that in growth will give rise to secondary emotions:

- joy, a feeling of satisfaction of the soul;

- envy, a strong desire to have what the other has;

- shame, an emotional reaction that one feels after having transgressed social rules;

- anxiety, reaction to a hypothetical danger, future and distant;

- resignation, willingness to patiently accept a pain, a misfortune;

- jealousy, an emotional state that comes from the fear of losing something;

- hope, a tendency to believe that phenomena or events are manageable and controllable and can therefore be directed towards hoped-for outcomes;

- forgiveness, replacement of negative emotions that follow a perceived offence with positive emotions;

- offense, moral damage caused to a person by acts or words;

- nostalgia, a state of malaise caused by the absence of a distant place, of a thing or person absent or of a finished situation that one would like to relive;

- remorse, state of distress or psychological upheaval experienced by those who feel that they have behaved or acted contrary to their moral code;

disappointment, state of mind of sadness caused by the verification that expectations do not occur in reality.

d) The attachment theory [11]: Emotions are at the basis of the interactions between caregiver and child, which will determine the onset of almost all known psychopathologies of the evolutionary age. As a result of these interactions, therefore, different styles of attachment can be formed in the child, as has been demonstrated in the Strange Situation (a procedure carried out by Bowlby [12] and his assistant Ainsworth, in which the child with his mother is introduced into a room full of toys. At various times the child is left alone or in the company of a stranger and then reunited with the mother to study the child's behaviour. Through these observations conducted in a welldefined setting, it has been possible to identify four patterns of child attachment: safe attachment and insecure attachment (with three types: avoidable, ambivalent and disorganised). From this we understand how emotions play a fundamental role in the interaction between adult and child by influencing important portions of behaviour. By expressing his or her emotions to the caregiver, the child is able to tune in to his or her needs in order to satisfy them (sufficiently good parent) [13], this allows the child to feel protected, nurtured and loved and therefore to be able to grow and develop.

Citation: Perrotta G, Fabiano G (2021) Behavioural disorders in children and adolescents: Definition, clinical contexts, neurobiological profiles and clinical treatments. Open J Pediatr Child Health 6(1): 005-015. DOI: https://dx.doi.org/10.17352/ojpch.000030 
Remaining on the subject of "attachment", it is easier to see the importance of basic emotions (anger, fear, sadness, disgust, contempt, surprise and joy) and how necessary they are for the child to be able to communicate with the reference figures in order to see their needs satisfied. Precisely for this reason, below, we will give examples that can show how emotions and anger in particular can be considered in a continuum between functional, non-functional and disfusional, producing behaviours from the most adaptive to maladaptive to pathological ones:

Adaptive situation for psycho-emotional development: In the case that the treatment satisfies the child, we will find a child who is balanced, safe, willing to explore the world of learning, who may have matured the management of frustrations and live his or her emotions, including anger in a balanced way. For example, when a child is told no, he or she will experience a common sense of frustration that will lead him or her to express anger, in turn, this emotion expressed towards the care-giver may lead him or her to console the child, thus containing the anger itself. From this simple example, we realise how over time this type of interaction can modulate the system of anger and its behavioural expression, as well as all other emotions. We therefore understand how any emotion as a form of communication and its modulation as feedback may or may not favour the child's emotional and cognitive evolution.

The psychosocial influence on psycho-emotional development: We consider less protective contexts for the child and his/ her development. For example, some very low socio-cultural environments, situations bordering on poverty or real poverty, suburbs of the world, where its inhabitants often experience secondary emotions such as: envy, shame, anxiety, resignation, jealousy, offense, remorse, disappointment. If these emotions are socially shared they can produce emotions of anger that translate into aggressive behaviour that in that specific contex are socially accepted. In these contexts the child needs to learn to read aggressive behaviour and to replicate it in turn. In those places that are well present in the news all over the world, showing aggressive behaviour becomes a form of adaptation that is fundamental for the survival of the individual. With this we could never say that all the inhabitants of any suburbs of the world who live those feelings and show aggression, are all violent people and have necessarily engaged in deviant or criminal behaviour. But we can say that in this context there may be more possibilities to develop deviant and pathological lifestyles. With these common examples we understand how emotions and especially anger, being a form of implicit communication, cannot be evaluated in an absolute sense, but always contextualized in a relationship and in a context. Therefore like any type of communication, always aimed at achieving the satisfaction of needs for this extremely adaptive. Without listing anthropological examples we know many violent and cruel practices aimed at parts of the community, which, being socially accepted, are not considered as such. In the above example we can understand how the socio-cultural dimension can influence the development of behaviour with respect to anger modulation; how aggressive behaviour is a real form of adaptation.
Situational circumstances not functional to the correct psychoemotional development: We see other situations, also very common. How many times have we happened to go shopping in the supermarket and see desperate children, crying and screaming very loud, throwing themselves on the floor because when asked to buy something the adult said no. When the child reacts with anger, we often notice that the caregiver is unable to contain the child's frustration and anger by being awkward and embarrassed by the situation. Imagine if this behaviour were replicated in a school environment, the child himself could experience great frustration and show inability to adapt to the context and its rules, potentially diminishing the possibility of integration with his peers and thus potentially increasing the discomfort. We see in this other example, common as the manifestation of anger, not having had modulation in the interaction with the caregiver or in the environment in which the child lives, does not allow the growth and psychoemotional development of the child, producing in it nonfunctional behaviour to integration.

Dysfunctionality: The last example is when the child lives, through violence and abuse [14], a continuous experience of rejection. This constant dissatisfaction with security generates in the child: emotional insensitivity, apathy, sense of inadequacy, making him or her live himself or herself as something inadequate, sick, incapable. In this possible situation we know that the child will not be able to live the emotions connected to these experiences, otherwise his survival would be lost, thus favouring a process of dissociation and removal [15]. We understand how the child's lack of emotional development will not allow him to develop those skills useful to sociality such as empathy, identification, moral sense, the limit of freedom. In this situation, there is a great increase in the possibility that the lack of modulation of anger can produce aggressive behaviour, first and then violent behaviour with social deviance, which could lead to a real psychopathology.

\section{Clinical and psychopathological profiles}

Behavioural disorders include a series of behaviours defined as "externalising", as they include behaviours in which internal discomfort is directed outwards through dysfunctional conduct such as aggressiveness, impulsiveness, challenge, violation of rules and other conduct considered socially inappropriate. At pre-school and school age, behavioural accesses may occur in an isolated and temporary manner, for example, when they are linked to situational aspects or to the particular stage of development in which the child finds himself or herself, or may represent real alarm bells ringing for the onset of future behavioural disorders. The ability to act appropriately in relation to social norms and to regulate one's own behaviour are two basic aspects of the child's development. However, these are complex abilities that are gradually acquired throughout childhood. Relying on the presence of the adult in regulating one's emotions and behaviour is fundamental for the child at least until the age of three. When such a young child is agitated or angry, he needs a reference figure who can calm him down and provide him with the most appropriate strategies to resolve his internal conflict. Just as in unfamiliar situations, if the

Citation: Perrotta G, Fabiano G (2021) Behavioural disorders in children and adolescents: Definition, clinical contexts, neurobiological profiles and clinical treatments. 
child shows fear and cries, it is the adult who will calm him/her down through loving behaviour and appropriate explanations. The child then learns to grasp the adult's signals, such as facial expressions, verbal communication and gestures, in order to be able to modulate his own way of expressing himself in the various contexts. Of great importance is the moment when the child goes from an adjustment based on the external support of the adult to a real self-regulation, i.e. when the child no longer needs to rely on external help and is able to have self-control even when the adult is not present. The critical period for acquiring this ability is usually between 24 and 36 months, the age at which the child begins to show that he or she knows how to internalise the adult's rules, how to wait to achieve something desired and can flexibly control his or her behaviour in the presence of environmental changes. Towards the end of the second year of life, children also begin to show that they are aware of the existence of social norms and their possible violation. It is currently believed that a deficit in selfregulation is relatively stable during childhood and plays a decisive role in the onset of certain problems of adaptation and regulation of behaviour at a later age. Several researchers have proposed different hypotheses with respect to the internal (emotional and cognitive) dynamics of the child, linked to the minor or greater ability to control his/her own behaviour. Some studies have shown that behavioural problems can be linked to: 1) low levels of fear in potentially harmful situations and reduced empathy towards one's peers, together with increased impulsiveness; 2) extremely high levels of emotional activation in the face of possible rewards, especially if associated with a rather high negative emotionality and low levels of selfcontrol. This means that in these children behavioural dysregulation can be linked to weak emotional activation in the face of possible punishments, which are thus minimised, or to very high emotional activation in the presence of potential rewards, which are then maximised. In other studies, moreover, it emerges that deficits in self-regulation are more associated with reactive aggressiveness (defensive response to a threat or provocation) than with proactive aggressiveness (aggressiveness expressed to gain an advantage or domination over others): in the former case, in fact, the minor shows difficulty in regulating his own emotions, for example his anger and frustration, when provoked by others. The inability to cope with this extreme internal activation thus leads to limitations in the development and use of one's own social skills, affecting interactions and the establishment of positive relationships with parents and peers; in the second case, on the other hand, when aggression is triggered without external provocation because it is aimed at obtaining personal gain, one can speak of traits more oriented towards provocation and challenge and of an evident difficulty in getting in touch with one's own and others' emotions [16-26].

In DSM-5 [17], the Diagnostic and Statistical Manual of Mental Disorders (APA, 2013), speaks about the so-called "Disruptive Behaviour, Impulse Control and Conduct Disorders" as a macrocategory to refer to a family of disorders in which the behavioural components of aggression and violation of norms are prevalent. In particular, reference is made to "intermittent explosive disorder", "conduct disorder" and "oppositional- provocative disorder"; however, a neurodevelopmental disorder called "attention deficit hyperactivity disorder" also falls into the category of behavioural disorders [28]. In detail:

1) The intermittent explosive disturbance: It refers to a behavioural picture where aggressiveness is dangerously acted out of the person's control and without adequate connection with the extent of the events taking place. The disorder is characterised by recurrent behaviour of explosive aggressiveness, verbal or physical, towards people or things that are potentially destructive and capable of causing serious damage. The aggressiveness acted in the intermittent explosive disorder is not only impulsive and uncontrolled, but clearly disproportionate to any stressful event or contingent provocation. People suffering from such disorders may experience episodes of exaggerated, unjustified and potentially damaging aggression for themselves or others, but such behaviour is a manifestation of a depressive or personality disorder and not primarily an expression of an inability to control impulses.

2) Conduct disorder: The main characteristic of this disorder is the systematic and persistent violation of the rights of others and social norms, with very serious consequences in terms of school and social functioning. Children and adolescents can show overbearing, threatening or intimidating behaviour, intentionally triggering fights, stealing objects by confronting the victim and forcing the other to suffer violence, even sexual abuse. The symptoms of the disorder are: assaults on people or animals; often bullies, threatens, or intimidates others; often starts physical fights; has used a weapon that can cause serious physical harm to others (e.g. a stick, a bar, a broken bottle, a knife, a gun); has been physically cruel to people and animals; has stolen by confronting the victim (e.g. assault, mugging, extortion, armed robbery); has forced someone into sexual activities; destruction of property; serious violations of rules.

3) Oppositional-provocative disorder: It involves problems of self-control of one's emotions and behaviour. In such disorders the described problems are expressed through behaviours that violate the rights of others, as in the case of aggression, destruction of property, or that place the person in sharp contrast with social norms or figures representing authority. Emotions such as anger and irritation, together with controversial and defiant behaviour, prevail. The frequency of the provocative oppositional disorder is higher in families where a parent has an antisocial disorder and is more common in children of biological parents with alcohol addiction, mood disorders, schizophrenia, or parents with a history of attention deficit hyperactivity disorder or conduct disorder. Oppositional provoking disorder is characterised by the frequent and persistent presence of an angry/irritable mood (he often gets angry, is often touchy or upset, is often angry and resentful), polemic/provocative behaviour (he often quarrels with people who represent authority, often openly challenges or refuses to respect the rules, deliberately irritates others, blames others for his own mistakes), vindictiveness. These symptoms must occur when interacting with at least one person other than a sibling and are often part of problematic ways of interacting with others. 
4) Attention deficit hyperactivity disorder: It is an evolutionary disorder of self-control. It includes difficulties in attention and concentration, impulse control and activity level. These problems derive substantially from the inability of the child to regulate his or her behaviour according to the passage of time, the objectives to be achieved and the demands of the environment. It should be pointed out that this morbid condition is not a normal growth phase that every child has to overcome, nor is it the result of an ineffective educational discipline, nor is it a problem due to the child's "wickedness". Known by the English acronym ADHD, it is a disorder with onset in developmental age ( $<12$ years) defined by five criteria (A, B, C, D, E) which must be present at the same time:

A. Persistent pattern of inattention and/or hyperactivityimpulsiveness that interferes with the functioning or development, as characterized by points 1 and/or 2:

1) Inattention: At least 6 of the following symptoms (from 17 years of age and over, five symptoms are sufficient) have persisted for at least six months with an intensity incompatible with the level of development, with a direct negative impact on social and school (or work) activities and the symptoms are not only a manifestation of oppositional behaviour, challenge, hostility or inability to understand tasks or instructions:

- often fails to pay attention to details or makes distracting mistakes in schoolwork, work or other activities (e.g. neglects or omits details, work is not accurate);

- often has difficulty maintaining attention on homework or play activities (e.g., has difficulty staying focused during a lesson, conversation or long reading);

- often the subject does not seem to listen when spoken to directly (for example, the mind seems elsewhere, even in the absence of obvious distractions);

- often the subject does not follow instructions and does not complete schoolwork, tasks or duties in the workplace (e.g. starts the activity but quickly loses concentration and is easily distracted);

- often has difficulty in organising tasks and activities;

- often avoids, feels aversion or is reluctant to engage in tasks that require protracted mental effort;

- often loses the objects needed for tasks or activities;

- is often distracted by external stimuli and is often careless in daily activities.

2) Hyperactivity and impulsiveness: At least 6 of the following symptoms (from 17 years of age and over, five symptoms are sufficient) persist for at least 6 months with an intensity incompatible with the level of development and having a direct negative impact on social and school/work activities:

- he often shakes or claps his hands and feet or wiggles in the chair;
- often leaves his seat in situations where one should remain seated (e.g. in the classroom, in the office or in other situations that require one to remain in one's seat);

- shrugs and jumps in situations where it is inappropriate to do so;

- is often unable to play or engage in leisure activities quietly;

- he is often "under pressure", acting as if he were "powered by a motor" (for example, he is unable to stand still, or feels uncomfortable doing so, for a prolonged period of time, such as in restaurants, during meetings);

- often speaks too much;

- often "shoots" an answer before the question has been completed (for example, he completes sentences said by others; he cannot wait his turn in conversations);

- often has difficulty waiting for his turn (e.g. while waiting in line);

- often interrupts others or is intrusive towards them (e.g., interrupts conversations, games or activities; can start using other people's things without asking or receiving permission; teenagers and adults can get involved or take over what others do).

B) The symptoms of inattention or hyperactivityimpulsiveness must have been present before the age of 12 years.

C) The different symptoms of inattention or hyperactivity must occur in at least two contexts such as at home, school or work, with friends or relatives or in other activities.

D) The symptoms must also interfere with the quality of social, school or work functioning.

E) The presence of a psychotic and/or mental disorder that can better justify the presence of symptoms is excluded.

DSM-5 [27] also lists other disorders related to emotional dysfunctionality, but this time with respect to attachment theory (attachment disorders), referring to the disturbed and/ or inadequate social relational mode, and are more related to disorders caused by traumatic and stressful events:

\section{1) Reactive attachment disorder}

\section{Two forms are known}

a) Inhibited type: the subject has difficulty in engaging in interpersonal relationships and responding adequately to them according to the level of development; there is excessive inhibition, hypervigilance and a contradictory attitude towards the caregiver. The inhibited type is characterised by the absence of organised attachment behaviour, low social involvement, difficulty in emotional regulation, hypervigilance, inexplicable fear and outbursts of anger;

Citation: Perrotta G, Fabiano G (2021) Behavioural disorders in children and adolescents: Definition, clinical contexts, neurobiological profiles and clinical treatments. Open J Pediatr Child Health 6(1): 005-015. DOI: https://dx.doi.org/10.17352/ojpch.000030 
b) Uninhibited type: he presents himself with the propensity to establish an indiscriminate sociability and an inadequate selectivity in the choice of the reference figure. The uninhibited type is characterised by the child's ease in moving away with strangers, the lack of search for family members in times of need and the absence of shyness towards the stranger with whom the contact is made.

The main manifestation is therefore the avoidance of figures called in technical terms caregivers, which may be parents or people other than parents who are in charge of caring/ assisting/care for the child. The absence of an attachment relationship with the caregiver can often be found in cases of neglect, or in technical terms neglect, abuse, abrupt separation from caregivers between 6 months and 5 years of age or lack of responsiveness on the part of the caregiver to the child who is trying to interact. In a context marked by humiliation and lack of comfort/support/protection from caregivers, these children soon develop a vision of themselves, others and the world based on personal inadequacy. Therefore, in the presence of such early experiences, withdrawal and avoidance are protective responses to pain and suffering. The conviction of not being accepted by others, the feeling of not belonging and having something wrong causes behaviours aimed at a constant attempt to protect oneself/defend oneself and the inability to regulate emotions in everyday life.

\section{2) Disorder of uninhibited social commitment}

Social neglect and traumatic experiences that occur from the first months of life can give rise to this disorder Children manifest a series of behaviours (verbal or physical) that are excessively familiar and devoid of inhibition in approaching and interacting with unknown adults, so much so that they are so reticent and hesitant to move away with them. These children are characterised by excessive emotionality. They show a general and marked happiness when they come into contact with strangers, which, on the other hand, may be completely absent in the case of caregivers (parents or persons other than parents who are responsible for the care/assistance/care of the child). When strangers reject their emotions and their search for attention they begin to show high levels of anxiety and frustration. The behaviour of attention-seeking and contact with unfamiliar adults, being characterised by a total violation of social-interpersonal boundaries (established by the culture of reference and age-appropriate), makes people around them feel uncomfortable and become suspicious of them. Uninhibited social behaviour also extends into adolescence and addresses the peer group, with whom superficial and conflictcharacterised relationships are soon established. These children show no remorse, guilt or sorrow when they hurt or disappoint those around them.

\section{3)Attachment disorder interrupted}

In the child it presents itself as the effect of traumatic separation from the attachment figure (parents or caregivers), frequent separation episodes or the psychological impact of grief following the death of the caregiver. The child with interrupted attachment disorder displays an insecure- disorganised behavioural pattern, i.e. highly dysfunctional with respect to the objective of attachment, which is to ensure the closeness and protection of the mother and/or caregiver This pathological behavioural model of the child can be found in the interaction with attachment figures, in conjunction with stressful life situations or separations. The child, in such contexts, shows behaviours that express great confusion and internal contradictions with respect to the relationship with the caregiver: for example, looking elsewhere while the mother takes him in her arms or while he tries to reach her, agitation, rigidity. Interrupted attachment disorder in the child expresses a global disturbance of the child's feeling of security and protection and develops within seriously dysfunctional relationships, in which the primary function of the attachment system is altered (that the child may experience a sense of internal security).

\section{The etiopathological and neurobiological profiles}

The origins of behavioural disorders may be of a different nature. In fact, there are many risk factors that contribute to defining a behavioural regulation problem. Among them, there are:

a) Biological and autonomic factors, i.e. altered levels of serotonin, dopamine, noradrenaline, oxytocin, testosterone and cortisol $[29,30]$.

b) Neurocognitive deficits of executive functions, difficulties in processing social information, congenital empathy deficits and prefrontal cortex anomalies [29,31-34].

c) Temperamental vulnerabilities, caused by reduced emotional regulation and impulsiveness [30,35].

d) Risk factors related to prenatal (exposure to toxins during pregnancy) and perinatal (poor quality of care immediately after childbirth) [30].

e) Coercive parental educational style and insecure or disorganised attachment style between child and reference adult [36].

f) Continuous conflicts within the family context, with exposure to violent acts, mistreatment or situations of abuse, which have exposed children to rejection or abandonment, have suffered excessively strict and frustrating discipline, early departure from the family nest, have suffered from organic diseases of some importance without having parents or adults attentive and understanding towards them, inconsistent or excessively permissive parental attitudes [37]. All these circumstances are capable of negatively affecting the child's future ability to have a solid and robust reality plan and a functional use of defence mechanisms $[38,39]$.

Recentemente uno studio con la risonanza magnetica ha dimostrato che i minorenni con un disturbo della condotta associato a tendenze psicopatiche hanno una diversa risposta emozionale se confrontati con determinati stimoli. I ragazzi che mostravano una specifica attivazione dell'amigdala e del corpo striato, erano più propensi a subire delle suggestioni,

Citation: Perrotta G, Fabiano G (2021) Behavioural disorders in children and adolescents: Definition, clinical contexts, neurobiological profiles and clinical treatments. 
quando partecipavano a liti di altri compagni. Diversamente dal gruppo di controllo, i ragazzi con il disturbo della condotta non riuscivano ad attivare le zone cerebrali ("corteccia paracingulata" e "giunture temporoparietali") coinvolte nella comprensione delle interazioni sociali e nell'attribuzione morale $[32,40]$.

Nevertheless, it is not uncommon to witness conditions that are associated with behavioural disorders, especially in adulthood and with the evolution of these morbid conditions into real personality disorders $[41,42]$, such as anxiety disorders [43] and panic disorders [44], post-traumatic stress [45,46] sleep disorders [47], depressive disorders [48] and suicidal risk [49], to be treated in psychotherapy [50] with possible pharmacological support.

\section{Treatments and therapy}

Children and adolescents with conduct disorders represent a large group of subjects with different characteristics in terms of: type of disorder, intensity, course, evolution and prognosis. Several authors also point out that aggressive and antisocial behaviour has a multifactorial etiopathogenesis associated with characteristics of the individual, family, peer group, school and socio-cultural context $[51,52]$.

Therefore, being a complex problematicity, different theories have tried to frame the phenomenon by triggering a large number of interventions with respect to the different orientations. For these reasons, the interventions taken into consideration below, will aim to report only a few explanatory examples with respect to the four types of intervention present in the literature.

The first group of interventions are aimed at minors, and consist of individual cognitive behavioural and relational therapies where animals are used. The second group are individual therapies of cognitive-behavioural and relational approach, addressed to parents. The third type of intervention are systemic relational family therapies. While in the last group we will examine are multi-modal interventions, where parental training sessions on parents and activities addressed to the class group are foreseen:

a) Individual intervention addressed to the child: The theory that inspired the interventions is the observation that the child, having suffered abuse of various kinds, replicates abusing behaviour without having the possibility of developing more adaptive ones [52]. In general, individual behavioural therapies [53-55], have the common objective of supporting the child in: recognising stimuli related to aggression and antisocial behaviour, modifying cognitive distortions, improving problem-solving skills and dealing with aggression and frustration. Therapies, therefore, focus on modifying the child's abilities in each of these areas [51,56]. In detail, the therapist, after identifying the problem-solving situation with the minor, supports him/her in generating different types of solutions and evaluating the positive or negative consequences of the behaviour, thus increasing his/her predictive capacity [55]. The main techniques used are: modeling exercises, role playing, reinforcement programmes such as token economy. Moreover, according to some authors [57], it is evident how the interspecies interaction typical of Assisted Interventions with Animals (IAA) in the psychotherapeutic and educational context can facilitate empathic attitudes, contributing to the emotional development of the child, increasing awareness and self-regulation capacity. Moreover, in the school context, this type of intervention with animals allows minors to better recognize and understand the experiences of personal and relational emotional life [58].

b) Individual intervention aimed at parents: Since maladaptive interaction between parents and children plays a pivotal role in the development of these pathologies, interventions have focused on undertaking a psychoeducational path that increases the family's social and relational skills [54]. For this reason, in general, interventions are often aimed at improving parenting skills and the relationship with children. From these objectives we find two groups of programmes: one of a behavioural type and one of a relational type, although we often find both elements combined. Cognitive therapy [56], aims to teach how to use positive reinforcement and punishment, through the use of prescriptions at home, role playing, shaping, situation recording on video, monitoring and verifying objectives. Among the best known interventions are Parent Management Training - Oregon (PMT-O) [59-61]. The aim of the programme is to educate parents to avoid coercive practices by assuming more spontaneous and consistent behaviour, through the use of rewards and small punishments, producing clear rules of behaviour for the child and giving him/her the opportunity to follow them. Parents will also be taught how to support children in solving everyday problems. The therapist works with them, usually at home, and only marginally interacts with the child.

c) Intervention aimed at the whole family: The basic assumption that inspired these interventions on the family nucleus is based on the observation that often the child's behaviour derives from the family dynamics experienced [52]. The Systemic approach programme by James Alexander and Bruce Parsons [62,63]. Functional Family Therapy (FFT) aimed at children with aggressive behaviour and/or substance abuse. Starting from the basic assumption that the household produces misbehaviour in the child. It is believed that by improving the quality of communication and interactions between all family members it is possible to produce pro-social change in the child [62]. The intervention is divided into different phases: engagment and motivations, behaviuor change and generalization. In the first phase the therapist, using cognitive techniques, tries to replace negative attitudes with positive attitudes, increasing his credibility and establishing a therapeutic alliance with all family members. In the second phase, the therapist, understanding the expectations that each member has towards the other members, tries to facilitate exchanges by identifying difficulties and developing problemsolving skills, thus restructuring relations between members. In the generalization phase, the therapist supports the family unit in extending the newly acquired skills to different contexts.

Citation: Perrotta G, Fabiano G (2021) Behavioural disorders in children and adolescents: Definition, clinical contexts, neurobiological profiles and clinical treatments. 
Multimodal intervention: Given the complexity of this type of disorders and the different levels (individual, family and social) of the problem, intervention programmes have been structured that can involve all levels at the same time: multimodal interventions. For this group we will examine the Coping Power programme of Lochman J. E. and Wells K.C. developed in 2002 [64-66]. The Coping Power Program consists of two parts, one aimed at parents and one aimed at the child in the class group. The objectives for the intervention on parents are: to develop the tendency to give positive attention to the child; to establish clear rules, expressing their expectations regarding the child's behaviour; to promote the ability to organise the study; to use appropriate educational practices such as small prizes and small punishments; to be able to recognise and modulate parental stress; to increase positive family communication and their problem-solving skills. The techniques used are group meetings structured in Parent Training sessions that aim to develop and strengthen parenting skills related to the different areas mentioned above. For the children, we try to teach them to recognise the physiological signs of emotions and in particular anger in order to be able to modulate it; learn the appropriate relational methods to become part of the peer group; develop the ability to resist stressful situations. Furthermore, the ability to recognise the point of view of others (perspective taking) is promoted and by acquiring better strategies for self-control, they will have more tools to resolve conflict situations in a more appropriate way. Moreover, it is foreseen the use of behavioural contracts (called "goals") in which minimum school objectives are set, agreed during the meetings with teachers, where the achievement of these is associated with a bonus system. Training on minors takes place by creating situations of "structured provocation" where members of the group act as emotional activators. In these controlled situations, the child directly experiences self-control exercises in order to increase the use of these techniques for anger management. The main tools used in the interaction of the class group is role-playing.

\section{Conclusions}

In conclusion, it emerges that disruptive behaviour, impulse control and conduct disorders have two important critical elements to take into account. The first is that these disorders, having a multi-dimensional etiology: the biological factor, the minor, the family and the social context, the interventions require a high level of complexity. The second data is that these disorders, often evolving into more complex personality disorders, such as the antisocial personality disorder, make it even more difficult to establish a good level of compliance, thus reducing the possibility of a positive resolution of the problem [67]. It is clear how these characteristics can significantly decrease the level of positive prognosis with a poor response to treatment. Different studies [51,68] show how multimodal interventions, embracing the different dimensions of the problem, can increase their level of effectiveness. In our opinion, even multimodal interventions have two important limits: the first is a high social cost and the second is that these interventions often deal with secondary or tertiary prevention, i.e. to intervene on subjects who already present problems. We understand that the time factor can play a fundamental role to treat these pathologies and have a positive resolution. On the basis of this evidence, in our modest opinion, it would be appropriate to highlight a series of predictive behaviours in children that can make it possible to anticipate a diagnosis of behavioural disorders, so as to intervene at an early stage and prevent them from developing into more serious personality disorders. In Italy, ISTAT, through research conducted annually in primary and secondary schools, has found that among the disorders present in school, mental disorders account for $73 \%$, of which $31.1 \%$ are attention and behaviour disorders [69]. These worrying data indicate an important increase in mental discomfort for children aged 6 to 12 years. Furthermore, studies conducted in the USA [70-72] have shown that in the prison population, the requirements for attention and behaviour disorders are often met. Therefore, understanding how these types of disorders can increase the likelihood of criminal activity in adulthood, our hypothesis is, that it may be desirable to increase the number of multi-modal primary prevention interventions aimed at families [73] and children between 6 and 12 years of age. This is because, in our opinion, they could nip the phenomenon in the bud, or at least reduce the population of those who may subsequently develop behavioural problems. If the hypothesis were confirmed, the costs of secondary and tertiary interventions would also be reduced. Moreover, the hypothesis of primary prevention interventions at an early age could increase the level of positive prognosis precisely because there would be no evolution in more complex diagnoses. In addition, the child would be prevented from encountering legal measures. Moreover, on the basis of what has been observed, it could be hypothesized that the spread of primary prevention programmes could considerably reduce: the use of drugs and the development of "criminal attitudes" [74-77], inevitably leading to a reduction in the resulting social cost, but this hypothesis should also be verified with systematic studies on these subjects.

\section{References}

1. Perrotta G (2019) Psicologia generale, Luxco Ed, 1st ed.

2. Perrotta G (2019) Psicologia dinamica, Luxco Ed, 1st ed

3. Cattarinussi B (2006) Sentimenti passione emozioni: le radici de comportamento sociale, Franco Angeli. Link: https://bit.ly/3184Jpc

4. Legrenzi P, Papagno C, Umiltà C (2012) Dal cervello alla mente, il Mulino

5. Zajonc RB (1980) Feeling and thinking: Preferences need no inferences American Psychologist 35: 151-175. Link: https://bit.ly/3shVO0o

6. LeDoux J (1998) Il cervello emozionale. Alle origini delle emozioni, Baldini \& Castaldi, Milano.

7. Lazarus RS (1993) Why we should think of stress as a subset of emotion. In L Goldberger \& S. Breznitz (Eds.), Handbook of stress: Theoretical and clinical aspects. Link: https://bit.ly/3vUVjeX

8. Stern DN (1985) II mondo interpersonale del bambino. Bollati Boringhieri, Torino. Link: https://bit.ly/3IFLmxk

9. Hill D (2015) Teoria della regolazione affettiva. Raffaello Cortina, Milano.

10. Ekman $P$ (2008) Te lo leggo in faccia. Riconoscere le emozioni anche quando sono nascoste. Editore Amrita, collana Scienza e Compassione.

Citation: Perrotta G, Fabiano G (2021) Behavioural disorders in children and adolescents: Definition, clinical contexts, neurobiological profiles and clinical treatments Open J Pediatr Child Health 6(1): 005-015. DOI: https://dx.doi.org/10.17352/ojpch.000030 
11. Perrotta G (2020) Dysfunctional attachment and psychopathological outcomes in childhood and adulthood. Open J Trauma 4: 012-021. Link: https://bit.ly/2Mi2ThB

12. Bowlby J (1989) Una base sicura, Raffaello Cortina Editore. Link: https://bit.ly/2NJU8Or

13. Winnicott W (1965) Sviluppo affettivo e ambiente. Armando Editore.

14. Panksepp J, Biven L (2014) Archeologia della mente, origini neuro-evolutive alle emozioni umane, Cortina Raffaello. Link: https://bit.ly/3cUjDoG

15. Steiner J (1996) I rifugi della mente, Bollati Boringhieri.

16. Brett ZH, Humphreys KL, Smyke AT, Gleason MM, Nelson CA, et al. (2015) Serotonin transporter linked polymorphic region (5-HTTLPR) genotype moderates the longitudinal impact of early caregiving on externalizing behavior. Dev Psychopathol 27: 7-18. Link: https://bit.ly/20YvkTm

17. Carliner H, Dahsan G, McLaughlin K, Keyes KM (2017) Trauma exposure and externalizing disorders in adolescents: Results from the national comorbidity survey adolescent supplement. J Am Acad Child Adolesc Psychiatry 56: 755764. Link: https://bit.ly/3d11ci6

18. Eisenberg N, Spinrad TL (2004) Emotion-related regulation: Sharpening the definition. Child Dev 75: 334-339. Link: https://bit.ly/3f7h5q4

19. Eisenberg N, Spinrad TL, Eggum ND (2010) Emotion-related self-regulation and its relation to children's maladjustment. Annu Rev Clin Psychol 6: 495525. Link: https://bit.ly/3d4S2RY

20. Fearon RMP, Belsky J (2011) Infant-mother attachment and the growth of externalizing problems across the primary-school years. J Child Psychol Psychiatry 52: 782-791. Link: https://bit.ly/3vR4ihc

21. Frick PJ, Morris AS (2014) Temperament and developmental pathways to conduct problems. J Clin Child Adolesc Psychol 33: 54-68. Link: https://bit.ly/398tYfx

22. Hoge RD, Guerra NG, Boxer P (2008) Treating the Juvenile Offender. New York: The Guilford Press. Link: https://bit.ly/319qWmV

23. Kochanska G, Coy KC, Murray KT (2001) The development of self-regulation in the first four years of life. Child Dev 72: 1091-1111. Link: https://bit.ly/3rdd7P1

24. Nigg JT (2006) Temperament and developmental psychopathology. J Child Psychol Psychiatry 47: 395-422. Link: https://bit.ly/3vN2ndP

25. Roskam I (2018) Externalizing behavior from early childhood to adolescence: Prediction from inhibition, language, parenting, and attachment. Dev Psychopathol 1-13. Link: https://bit.ly/2QIEBFh

26. Van Nieuwenhuijzen M, Van Rest MM, Embregts PJCM, Vriens A, Oostermeije $S$, et al. (2017) Executive functions and social information processing in adolescents with severe behavior problems. Child Neuropsychology 23: 1-14 Link: https://bit.ly/3ILAwpx

27. American Psychiatric Association (2013) Diagnostic and statistical manual of mental disorders (5th ed.). Washington, DC

28. Perrotta G (2019) Psicologia clinica, Luxco Ed, 1th ed.

29. Frick PJ, Stickle TR, Dandreaux DM, Farrell JM, Kimonis ER (2005) Callous unemotional traits in predicting the severity and stability of conduct problems and delinquency. J Abnorm Child Psychol 33: 471-487. Link: https://bit.ly/3f3mNsz

30. Lahey BB, Waldman ID (2003) A developmental propensity model of the origins of conduct problems during childhood and adolescence. In B.B. Lahey, T.E. Moffitt, A. Caspi, Causes of conduct disorder and juvenile delinquency 76 117. Link: https://bit.ly/3sqX4yF

31. Eisenberg $N$ (2005) Age changes in prosocial responding and moral reasoning in adolescence and early adulthood. J Res Adolesc 15: 235-260. Link: https://bit.ly/3ccKuNs
32. Decety J, Meyer M (2008) From emotion resonance to empathic understanding: a social developmental neuroscience account, Dev Psychopathol 20: 1053 1080. Link: https://bit.ly/2PkwGrc

33. Blair RJR (2005) Responding to the emotions of others: Dissociating forms of empathy through the study of typical and psychiatric populations. Conscious Cogn 14: 698-718. Link: https://bit.ly/3tKI1RA

34. Perrotta G (2019) Executive functions: definition, contexts and neuropsychological profiles. J Neuroscience and Neurological Surgery 4: 4-77. Link: https://bit.ly/38KeX2l

35. Herpertz SC, Sass H (2000) Emotional deficiency and psychopathy. Behavioral Science and Law 18: 567-580. Link: https://bit.ly/31alW0c

36. Foley HA, Carlton CO, Howell RJ (1996) The relationship of attention deficit hyperactivity disorder and conduct disorder to juvenile delinquency: legal implications. Bull Am Acad Psychiatry Law 24. Link: https://bit.ly/3IJrl8Z

37. Wollff S (1969) Paure e conflitti nell'infanzia, Roma, Armando Editore.

38. Perrotta G (2019) The reality plan and the subjective construction of one's perception: the strategic theoretical model among sensations, perceptions, defence mechanisms, needs, personal constructs, beliefs system, social influences and systematic errors. J Clinical Research and Reports 1. Link: https://bit.ly/3b34baH

39. Perrotta G (2020) Human mechanisms of psychological defence: definition historical and psychodynamic contexts, classifications and clinical profiles. Int J Neurorehabilitation Eng 7: 1. Link: https://bit.ly/2L0I5dJ

40. Decety J, Michalska KJ, Akitsuki Y (2008) Who caused the pain? A functional MRI investigation of empathy and intentionality in children. Neuropsychologia 46: 2607-2614. Link: https://bit.ly/3rmlAj7

41. Perrotta G (2020) Borderline Personality Disorder: definition, differential diagnosis, clinical contexts and therapeutic approaches. Ann Psychiatry Treatm 4: 043-056. Link: https://bit.ly/3hx2B1N

42. Perrotta G (2020) Narcissism and psychopathological profiles: definitions, clinical contexts, neurobiological aspects and clinical treatments. J Clin Cases Rep 4: 12-25. Link: https://bit.ly/2KCwxOa

43. Perrotta G (2019) Anxiety disorders: definitions, contexts, neural correlates and strategic therapy. J Neur Neurosci 6: 046. Link: https://bit.ly/2WSmiaT

44. Perrotta G (2019) Panic disorder: definitions, contexts, neural correlates and clinical strategies. Current Trends in Clinical \& Medical Sciences 1. Link: https://bit.ly/38IG6D5

45. Perrotta G (2019) Post-traumatic stress disorder: Definition, contexts, neura correlations and cognitive-behavioral therapy. J Pub Health Catalog 2: 40-47. Link: https://bit.ly/3rvaCc6

46. Perrotta G (2020) Psychological trauma: definition, clinical contexts, neural correlations and therapeutic approaches. Curr Res Psychiatry Brain Disord: CRPBD-100006. Link: https://bit.ly/37UD3bz

47. Perrotta G (2019) Sleep-wake disorders: Definition, contexts and neural correlations. J Neurol Psychol 7: 09. Link: https://bit.ly/3hoBiGO

48. Perrotta G (2019) Depressive disorders: Definitions, contexts, differential diagnosis, neural correlates and clinical strategies. Arch Depress Anxiety 5 009-033. Link: https://bit.ly/2KADvDm

49. Perrotta G (2020) Suicidal risk: definition, contexts, differential diagnosis neural correlates and clinical strategies. J Neuroscience Neurological Surgery 6: 114. Link: https://bit.ly/3aMqcu5

50. Perrotta G (2020) The strategic clinical model in psychotherapy: theoretical and practical profiles. J Addi Adol Behav 3: 5. Link: https://bit.ly/3aPMx9X

51. Henggeler SW, Lee T (2003) Multisytemic treatment of seriuos clinical

Citation: Perrotta G, Fabiano G (2021) Behavioural disorders in children and adolescents: Definition, clinical contexts, neurobiological profiles and clinical treatments. Open J Pediatr Child Health 6(1): 005-015. DOI: https://dx.doi.org/10.17352/ojpch.000030 
problems. in Kazedin AE, Weisz Jr, Edivedence-based Psychoraphies for children and adolescents, Guilde for press, New York. Link: https://bit.ly/3f7fAYY

52. Nock MK (2003) Progress review of the psychosocial treatment of child conduct problems. Clinical Psychology Science and Practice 10: 1-28. Link: https://bit.ly/3se9M3F

53. Brinkmeyer MY, Eyberg SM (2003) Parent- child interaction therapy for oppositional children. In A.E. Kazdin, J.R. Weisz Evidence-based Psychoperapies for children and adolescents. Guilford Press New-York.

54. Kazdin AE, Whitley MK (2003) Treatment of parental stress to enhance therapeutic change among children referred for aggressiv behaviour. J Consult Clin Psychol 71: 504-515. Link: https://bit.ly/3IIZRAz

55. Eyberg SM, Nelson MM, Boggs SR (2008) Evidence-based Psychosocial Treatment for Children and adolescent with distructive behaviour. J Clin Child Adolesc Psychol 37: 215-237. Link: https://bit.ly/3vPY55

56. Ruguglioni L, Muratori P, Polidori L, Manfredi A, Lambruschi F (2009) ॥ trattamento Multi-Modale dei Disturbi da comportamento dirompente in bambini in età scolare: Presentazione di un'esperienza. Cognitivismo Clinico, Giovanni Fioriti Editore s.r.I 200-230.

57. Melchiori FM, Barzotti I (2018) Pet therapy nel contesto di apprendimento: effetti cognitivi ed emozionali, Rivista internazionale di Scienze dell'Educazione e della Formazione 16: 374-382. Link: https://bit.ly/3f5yJdA

58. Brelsford VL, Meints K, Gee NR, Pfeffer K (2017) Animal-Assisted Interventions in the Classroom - A systematic review. Int J Environ Res Public Health 14 669. Link: https://bit.ly/3tPYdzl

59. Patterson GR, Gullion ME (1968) Living with children: New methods for parents and teachers, Champaign, IL: Research Press.

60. Patterson GR, Reid JB, Jones RR, Conger RE (1975) A social learning approach to family intervention: Families with aggressive children (Vol. 1), Eugene, OR: Castalia.

61. Patterson GR, Chamberlain P, Reid JB (1982) A comparative evaluation of a parent training program. Behav Ther 13: 638-650. Link: https://bit.ly/3caNMAP

62. Alexander J, Parsons B (1973) Short-term behavioral inter-vention with delinquent families: Impact on family processand recidivism. J Abnorm Psychol 81: 219-225. Link: https://bit.ly/3cdYR4s

63. Alexander J, Pugh C, Parsons B (2000) Functional Family Therapy. University of Colorado, Institute of Behavioral Science.

64. Lochman JE, Wells KC (2002) The Coping Power Program at themiddle schol transition: Universal and indicated prevention effects. Psychol Addict Behav 16: S40- S54. Link: https://bit.ly/20Yo75M

65. Lochman JE \& Wells KC (2003) Effectiveness study of Coping Power and classroom intervention with aggressive children: Outcomes at aone-year follow-up. Behaviour Therapy 34: 493-515.

66. Bertacchi I, Giuli C, Muratori P (2016) Coping Power nella scuola primaria: gestire i comportamenti problematici e promuovere le abilità relazionali in classe, Trento: Erickson

67. Kazdin AE, Wassel G (2000) Therapeutic changes in children, parents and families resulting for treatment of children with conduct problems. J Am Acad Child Adolesc Psychiatry 39: 414-420. Link: https://bit.ly/3rfFzQh

68. Lochman JE, Wells KC (2004) The Coping Power Program for Preadolescent Aggressive Boys and Their Parents: Outcome Effects at the 1-Year Follow-Up. J Consult Clin Psychol 72: 571-578. Link: https://bit.ly/3tNyEQ8
69. Istat report (2018) La salute mentale nelle varie fasi della vita, 2015-2017.

70. Vitelli R (1996) Prevalence of childhood conduct and attention-deficit hyperactivity disorders in adult maximum-security inmates. Int $\mathrm{J}$ Offender Ther Comp Criminol 40: 263-271. Link: https://bit.ly/2PfrYLw

71. Young SJ, Adamou M, Bolea B, Gudjonsson G, Müller U, et al. (2011) The identification and management of ADHD offenders within the criminal justice system: a consensus statement from the UK Adult ADHD Network and criminal justice agencies. BMC Psychiatry11: 32. Link: https://bit.ly/3f3yZtK

72. Eyestone LL, Howell RJ (1994) An epidemiological study of attention-deficit hyperactivity disorder and major depression in a male prison population. Bull Am Acad Psychiatry Law 22: 181-193. Link: https://bit.ly/3180biC

73. Moffitt TE (1993) Adolescence-limited and life-course-persistent antisocia behavior: a developmental taxonomy. Psychol Rev 100: 674-701. Link: https://bit.ly/39amtVo

74. Santinello M, Cenedese C (2002) L'efficacia della prevenzione e la prevenzione dell'inefficacia. Alcune riflessioni sui programmi preventivi per i minori, Psicologia Clinica dello sviluppo 37-64. Link: https://bit.ly/31clG1Q

75. Mastronardi V (2002) Comunicazione in famiglia e prevenzione primaria, Ann Ist Super Sanità 38: 259-263. Link: https://bit.ly/3sg3U9M

76. Garnier HE, Stein AJ (2002) An 18-year model of family and peer effects on adolescent drug use and delinquency. Journal Youth Adolescence 31: 45-56. Link: https://bit.ly/3vTOFpi

77. Pietralunga S, Grattagliano I, Lalla M, Bologna M (2020) Minori e attività sportive: una ricerca-intervento per la prevenzione primaria della devianza minorile. Il contributo della criminologia, Rassegna Italiana di Criminologia 14 $122-125$

Discover a bigger Impact and Visibility of your article publication with Peertechz Publications

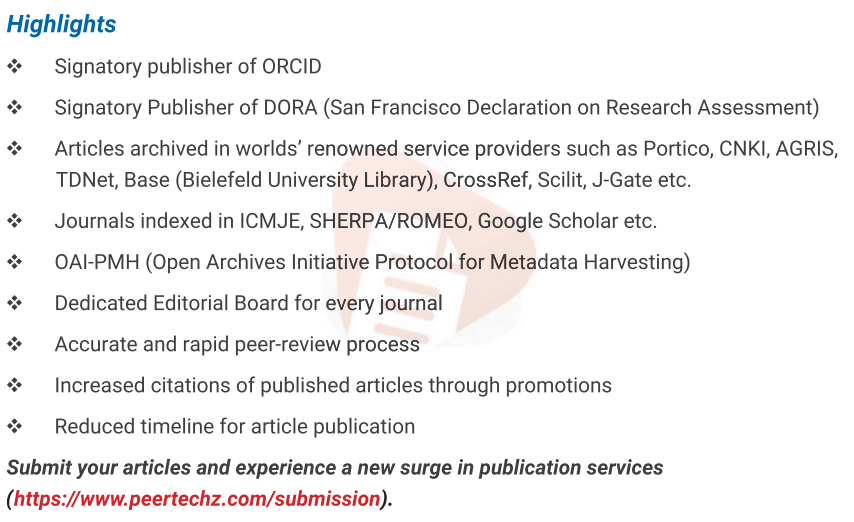

Peertechz journals wishes everlasting success in your every endeavours.

Copyright: @ 2021 Perrotta G, et al. This is an open-access article distributed under the terms of the Creative Commons Attribution License, which permits unrestricted use, distribution, and reproduction in any medium, provided the original author and source are credited.

Citation: Perrotta G, Fabiano G (2021) Behavioural disorders in children and adolescents: Definition, clinical contexts, neurobiological profiles and clinical treatments Open J Pediatr Child Health 6(1): 005-015. DOI: https://dx.doi.org/10.17352/ojpch.000030 